\title{
Discussion on Technical Problems and Development Suggestions of Engineering Drilling Rig Automation
}

\author{
Kaijun Li ${ }^{1^{*}}$, Zibo Di ${ }^{2}$ \\ ${ }^{1}$ College of Construction Engineering, Jilin University, Changchun 130026, Jilin Province, China. E-mail: \\ 1290361233@qq.com \\ ${ }^{2}$ School of Mechanical and Aerospace Engineering, Jilin University, Changchun 130022, Jilin Province, China
}

\begin{abstract}
As one of the important technologies in the mining industry, the drilling machine technology can improve the efficiency and quality of the mining industry. Compared with the traditional drilling machine technology, the drilling machine automation technology is obviously more reliable. Drilling automation technology can not only optimize the traditional mining efficiency, but also ensure the safety of people in the mining process. At present, the automatic drilling machine is the highest level of drilling technology in China. In the process of the automatic drilling machine, the downhole closed-loop technology can be used. This technology can completely separate from the human control and automatically complete the task only by transferring the information to the underground central computer.
\end{abstract}

Keywords: Drilling Rig; Automation Technology; Technical Problems and Suggestions

There are some hidden dangers in the traditional drilling technology. The drilling machine is to use certain mechanical equipment to drill the surface of the earth into a certain depth of the cylindrical hole. In this process, the construction personnel should select the appropriate location and bit for construction operation. In the whole process, the construction personnel should observe every move of the drilling machine. Some bits will fall off during the construction process. The traditional drilling machine technology is to use a large number of human resources to get familiar with the construction site, and select the appropriate geographical location for operation, and transmit. Under the unified drilling technology operation, not only the operation process is tedious and difficult, but also the safety of construction personnel can not be guaranteed. Compared with the traditional technology, automation technology has many advantages.
But at the same time, its disadvantages are also very obvious. It still needs to be improved reasonably to give full play to its advantages.

\section{Advantages of adopting drilling automation technology}

Compared with other countries, the development of drilling technology in China is slow, so many problems in the mining process, which is relatively difficult to deal with, will be encountered. In the face of these difficult problems, it is necessary to learn to apply the drilling automation technology, and continue to inherit the automation of drilling technology. The automation of drilling technology will help to solve the problems encountered in mining, improve the mining efficiency, and reduce the mining difficulty in China. Compared with those developed countries, the traditional drilling

\footnotetext{
Copyright (C) 2020 Kaijun Li and Zibo Di

doi: $10.18282 /$ fme.v2i2.872

This is an open-access article distributed under the terms of the Creative Commons Attribution Non-Commercial License

(http://creativecommons.org/licenses/by-nc/4.0/), which permits unrestricted non-commercial use, distribution, and reproduction in any medium, provided the original work is properly cited.
} 
technology of China is relatively backward, and the mining cost will be relatively increased in the backward process. Therefore, the application of drilling automation technology can not only help to solve the problems of low efficiency and high cost in the production process, but also make the drilling technology in China get no The increase of fault will take up more and more proportion in the main mining technology of China ${ }^{[1]}$.

Compared with other countries, the development of drilling technology in China is slow, so many problems in the mining process will be encountered, which is relatively difficult to deal with. In the face of these difficult problems, it is necessary to learn to apply the drilling automation technology, and continue to inherit the automation of drilling technology. The automation of drilling technology will help to solve the problems encountered in mining, improve the mining efficiency, and reduce the mining difficult. Compared with those developed countries, the traditional drilling technology of China is relatively backward, and the mining cost will be relatively increased in the backward process. Therefore, the application of drilling automation technology can help to solve the problems of low efficiency and high cost in the production process. The increase of fault will take up more and more proportion in the main mining technology of China.

The automation of drilling technology can improve the level of mining resources to a certain extent, so as to effectively remove the traditional drilling technology. The traditional drilling technology is carried out with human resources, which will consume a lot of human resources in the process of drilling, and can not guarantee the safety of these human resources. If the operation is not correct, it may lead to the loss of life of the staff, and also waste a lot of mining costs in the process of operation. After the automation of drilling technology is used, not only the human resources and mining costs can be saved, but the safety and security of staff also can be ensured.

\section{Problems faced by automation technology}

\subsection{The initial cost of adopting automation technology}

Compared with traditional technology, rig automation technology does have many advantages over the former, but there are also certain problems in itself that need to be improved. The use of drilling rig automation technology requires advanced automation equipment support, and it also requires a certain amount of manpower and material to repair and maintain. These all require enterprises to spend a large amount of expenses. There are some companies that do not have long-term vision and still prefer to look like The traditional drilling rig technology, which costs relatively little, causes the application of the drilling rig automation technology to be still not widely used ${ }^{[2]}$.

\subsection{Operator technical training issues}

A serious problem is still faced by enterprises that the traditional technology is the cause of weak professional skills and insufficient proficiency of operators. The introduction of new technologies requires employees to master a new operation technology, but the employees' awareness of innovation is not strong. The enthusiasm for learning is not high, which causes a certain repulsion of the rig automation technology and is very unfavorable for the promotion and application of automation technology. Even if the operator is not proficient in professional technology and passes the assessment, he cannot operate the equipment at will. If the precision operation is not careful, it will cause serious consequences. This situation also requires the operator and the management to pay attention to it.

\subsection{Problems related to disordered field wiring}

Automation technology needs the support of automation equipment, and the more equipment, the more cables are connected. The phenomenon that cables are disorderly walking and disorderly coiled on the ground is often seen at the operation site. This kind of problem will not only increase the risk factors, but also cause great trouble in the storage link at the end of the work, thus increasing a certain amount of work, so the manufacturer can consider the convenience of storage while manufacturing the equipment, and it will be more convenient to assemble the cables together; the enterprises using the equipment can also install some small facilities for sorting and storage by themselves, so as to use them. All kinds of cables shall be placed in 
order to improve the safety, beauty and convenience of operation.

\section{Problems with regulating automation equipment}

Computer technology and information technology are important parts of drilling machine technology automation, and these technologies need to be based on the control of drilling machine automation equipment, so as to create strong conditions for drilling machine technology automation. First of all, logic expression technology should be adopted, which can improve the level of information technology processing, at the same time, make a reasonable and simple plan for the automation of drilling technology, and provide a reference for the staff. Secondly, information transfer technology must be used to create a kind of information transfer function, which can transfer information to the control center on the ground, so as to ensure the smooth operation of the drilling rig.

Finally, it is necessary to use the computer network technology to build an automatic control platform. Because computer network technology is used to simulate and analyze the drilling process, and fix various wrong data information in the process, so understanding the problem of regulating automation equipment is very important. It is the information transmission function of the equipment, only in this way can the drilling machine work smoothly[3].

\section{Countermeasures for development of drilling automation technology}

Because the automation technology of drilling machine plays a very important role in the mining process. Although the automation technology is much better than the traditional drilling machine technology, there will also serve as some shortcomings. Therefore, more attention should be paid to the following requirements when using the automation equipment of a drilling machine. Relevant workers need to understand how to use the automation equipment and can use modern technology, such as computer network technology for drilling work. Finally, some suggestions should be submitted. In the process of drilling, it is necessary in order to understand the development trend of drilling technology. Compared with the traditional drilling technology, the investment cost of drilling automation technology is relatively high, and the relevant government departments are required to offer more support of drilling technology in China. Through capital investment and policy support, the researchers in China are carrying out technical research in order to promote the development of drilling technology in China, sufficient funds should be and good equipment for technical research.

\subsection{Master the application of automation equipment}

As an indispensable part of the mining process, the drilling rig technology should be able to accurately detect the exact location of the resources to be mined in the process of use, and provide accurate and reliable data for the drilling rig technology. In the process of drilling rig technology automation, it is necessary to use intelligent technology and advanced equipment to make accurate detection. First, intelligent equipment needs to be used to accurately locate the resources to be mined; secondly, other intelligent positioning systems are used to locate the resources again to ensure the accuracy of the location of mining resources; finally, according to the results of comprehensive analysis, the parameters of mining resources should be determined to provide a guarantee for drilling technology. Unlike the traditional drilling technology, which relies on human resources to determine the exact location of drilling, the current drilling automation technology can automatically confirm and be accurate.

\subsection{Application with computer network}

The automation of drilling technology needs the help of computer network, because computer is the platform of automation equipment, which can help us to integrate and analyze the data. This kind of computer network plays a very important role in the process of drilling rig automation. First, computer network technology can be used to analyze the data of drilling rig technology comprehensively, sort out and divide the data resources, and apply these data to drill rig technology pertinently, which can greatly improve the accuracy of drilling rig technology. Thirdly, the fault-tolerant 
function technology can be used to solve the problem of external interference of the database, avoid the leakage of the drilling technology information, improve the database security of the drilling technology, and ensure the authenticity and accuracy of the stored information.

\subsection{Solve problems in enterprise application}

It is important to strengthen the innovation awareness of enterprises and internal staff, follow the trend of the time, understand the advantages of drilling automation technology, and use innovative technology to reasonably replace the traditional manual operation. At the same time, it is also necessary to regularly organize and carry out skills training on rig automation technology, and strengthen the professional and technical mastery of internal operators. At the same time, more attention should be paid to the details of the operation, especially the chaos of the ground wire and improve the security, and at the same time, most of the unnecessary workload for the later processing can be saved.

\subsection{Suggestions on the technical prospect of drilling rig}

Compared with the traditional drilling technology and the automatic drilling technology, the automatic drilling technology has obviously reflected the trend of intelligence. The automatic drilling technology is constantly developing in a new direction. Therefore, in this process, continuous attention should be paid to the automatic drilling technology. The scientific researchers should strengthen the research on the drilling technology to make it continue to develop, and the Chinese government also It is necessary to pay attention to the drilling rig technology and increase financial support for its scientific research and research, so that the drilling rig technology in China has sufficient capital investment in scientific research and research ${ }^{[4]}$. Therefore, for the prospect analysis of drilling technology, relevant researchers must understand the development trend of the times and keep up with the pace of the times. It is China's drilling technology to develop intelligently, strengthen technical research and promote the development of drilling technology in China. At the same time, Chinese government also needs to give full support to drilling technology, through financial support and technical support, so as to truly promote the development of drilling technology .

\section{Conclusion}

Through the above learning, it is found that the traditional drilling machine technology has certain potential safety hazards, and will consume a lot of human resources and mining costs. Therefore, it is important to improve the automation level of drilling machine technology, apply the automation of drilling machine technology to effectively solve the problems encountered in resource mining, improve mining efficiency, reduce the cost of resource mining, and use computer network technology to improve the accuracy of positioning. Therefore, in the process of drilling machine technology automation, research should be conducted from various aspects and practice in the process of research. At the same time, some problems faced by the drilling automation technology should be aware.

\section{References}

1. Li J. Research on drilling rig automation technology (in Chinese). Automation Technology 2017; (21): 267.

2. Zhang Z. Research on technical problems and development measures of drilling rig automation (in Chinese). Automation Technology 2016; (11): 80-84.

3. Li L, Zou Y. Discussion on technical problems and development suggestions of engineering drilling rig automation (in Chinese). Industrial Design 2016; (8): 171-172.

4. Lu J. Analysis on technical problems and development measures of drilling automation (in Chinese). Automation Technology 2016; (22): 23-28. 